\title{
Genetic signatures of Mycobacterium tuberculosis Nonthaburi genotype revealed by whole genome analysis of isolates from tuberculous meningitis patients in Thailand
}

Olabisi Oluwabukola Coker, Angkana Chaiprasert, Chumpol Ngamphiw, Sissades Tongsima, Sanjib Mani Regmi, Taane G Clark, Rick Twee Hee Ong, Yik-Ying Teo, Therdsak Prammananan, Prasit Palittapongarnpim

Genome sequencing plays a key role in understanding the genetic diversity of Mycobacterium tuberculosis (M.tb). The genotype-specific character of $M$. tb contributes to tuberculosis severity and emergence of drug resistance. Strains of $M$. tb complex can be classified into seven lineages. The Nonthaburi (NB) genotype, belonging to the IndoOceanic lineage (lineage 1), has a unique spoligotype and IS6110-RFLP pattern but has not previously undergone a detailed whole genome analysis. In addition, there is not much information available on the whole genome analysis of $M$. th isolates from tuberculous meningitis (TBM) patients in public databases. Isolates CSF3053, 46-5069 and 43-13838 of NB genotype were obtained from the cerebrospinal fluids of TBM Thai patients in Siriraj Hospital, Bangkok. The whole genomes were subjected to high throughput sequencing. The sequence data of each isolate were assembled into draft genome. The sequences were also aligned to reference genome, to determine genomic variations. Single nucleotide polymorphisms (SNPs) were obtained and grouped according to the functions of the genes containing them. They were compared with SNPs from 1,601 genomes, representing the seven lineages of $M$. tb complex, to determine the uniqueness of NB genotype. Susceptibility to first-line, second-line and other antituberculosis drugs were determined and related to the SNPs previously reported in drug resistant related genes. The assembled genomes have an average size of 4,364,461 bp, 4,154 genes, 48 RNAs and 64 pseudogenes. A 500 base pairs deletion, which includes ppe50, was found in all isolates. RD239, specific for members of Indo Oceanic lineage, and RD147c were identified. A total of 2,202 SNPs were common to the isolates and used to classify the NB strains as members of sublineage 1.2.1. Compared with 1,601 genomes from the seven lineages of $M$. tb complex, mutation $\mathrm{G} 2342203 C$ was found novel to the isolates in this study. Three mutations (T28910C, C1180580T and C152178T) were found only in Thai NB isolates, including isolates from previous study. Although drug susceptibility tests indicated pan-susceptibility, non-synonymous SNPs previously reported to be associated with resistance to anti-tuberculous drugs; isoniazid, ethambutol, and ethionamide were 
identified in all the isolates. Non-synonymous SNPs were found in virulence genes such as the genes playing roles in apoptosis inhibition and phagosome arrest. We also report polymorphisms in essential genes, efflux pumps associated genes and genes with known epitopes. The analysis of the TBM isolates and the availability of the variations obtained will provide additional resources for global comparison of isolates from pulmonary tuberculosis and TBM. It will also contribute to the richness of genomic databases towards the prediction of antibiotic resistance, level of virulence and of origin of infection. 


\section{Title page}

2

3 Genetic signatures of Mycobacterium tuberculosis Nonthaburi genotype revealed by whole

4 genome analysis of isolates from tuberculous meningitis patients in Thailand.

6 Olabisi Oluwabukola Coker ${ }^{1}$, Angkana Chaiprasert ${ }^{1 \#}$, Chumpol Ngamphiw ${ }^{2}$, Sissades

7 Tongsima ${ }^{2}$, Sanjib Mani Regmi ${ }^{3}$, Taane G. Clark ${ }^{4,5}$, Ong Twee Hee ${ }^{6}$, Teo Yik Ying ${ }^{6}$ Therdsak

8 Prammananan $^{2}$, Prasit Palittapongarnpim ${ }^{7}$,

$10{ }^{1}$ Department of Microbiology, Faculty of Medicine Siriraj Hospital, Mahidol University,

11 Bangkok 10700, Thailand, bisistill@yahoo.com

$12{ }^{2}$ National Center for Genetic Engineering and Biotechnology, National Science and Technology

13 Development Agency, Pathum Thani 12120, Thailand.

$14{ }^{3}$ Department of Microbiology, Gandaki Medical Collage, Pokhara, Kaski, Nepal.

$15{ }^{4}$ Faculty of Infectious and Tropical Diseases, London School of Hygiene and Tropical Medicine,

16 London, United Kingdom

$17{ }^{5}$ Faculty of Epidemiology and Population Health, London School of Hygiene and Tropical

18 Medicine, London, United Kingdom.

$19{ }^{6}$ Saw Swee Hock School of Public Health, National University of Singapore, Singapore.

$20{ }^{7}$ Department of Microbiology, Faculty of Science Mahidol University, Bangkok 10400, 21 Thailand. 
25 \#Corresponding author

26 Angkana Chaiprasert, Dr. rer. nat.

27 Department of Microbiology

28 Faculty of Medicine Siriraj Hospital, Mahidol University

292 Wanglang Rd., Bangkok-Noi, Bangkok 10700, Thailand

30 Tel. 66-2-419-8256

31 Fax. 66-2-418-2054

32 E-mail. angkana.cha@mahidol.ac.th 


\section{Abstract}

53 Background. Genome sequencing plays a key role in understanding the genetic diversity of Mycobacterium tuberculosis. The genotype-specific character of M. tuberculosis contributes to tuberculosis severity and emergence of drug resistance. Strains of M. tuberculosis complex can be classified into seven lineages. The Nonthaburi genotype, belonging to the Indo-Oceanic

57 lineage (lineage 1), has a unique spoligotype and IS6110-RFLP pattern but has not previously undergone a detailed whole genome analysis. In addition, there is not much information available on the whole genome analysis of M. tuberculosis isolates from tuberculous meningitis

60 patients in public databases.

61 Methods. Isolates CSF3053, 46-5069 and 43-13838 of Nonthaburi genotype were obtained from

62 the cerebrospinal fluids of tuberculous meningitis Thai patients in Siriraj Hospital, Bangkok. The

63 whole genomes were subjected to high throughput sequencing. The sequence data of each

64 isolate were assembled into draft genome.

65 The sequences were also aligned to reference genome, to determine genomic variations. Single

66 nucleotide polymorphisms (SNPs) were obtained and grouped according to the functions of the

67 genes containing them. They were compared with SNPs from 1,601 genomes, representing the 68 seven lineages of M. tuberculosis complex, to determine the uniqueness of Nonthaburi genotype. 
69 Susceptibility to first-line, second-line and other antituberculosis drugs were determined and

70 related to the SNPs previously reported in drug resistant related genes.

71 Results. The assembled genomes have an average size of 4,364,461 bp, 4,154 genes, 48 RNAs

72 and 64 pseudogenes. A 500 base pairs deletion, which includes ppe50, was found in all isolates.

73 RD239, specific for members of Indo Oceanic lineage, and RD147c were identified.

74 A total of 2,202 SNPs were common to the isolates and used to classify the Nonthaburi strains as

75 members of sublineage 1.2.1. Compared with 1,601 genomes from the seven lineages of $M$.

76 tuberculosis complex, mutation G2342203C was found novel to the isolates in this study. Three

77 mutations (T28910C, C1180580T and C152178T) were found only in Thai Nonthaburi isolates,

78 including isolates from previous study. Although drug susceptibility tests indicated pan-

79 susceptibility, non-synonymous SNPs previously reported to be associated with resistance to

80 anti-tuberculous drugs; isoniazid, ethambutol, and ethionamide were identified in all the isolates.

81 Non-synonymous SNPs were found in virulence genes such as the genes playing roles in

82 apoptosis inhibition and phagosome arrest. We also report polymorphisms in essential genes,

83 efflux pumps associated genes and genes with known epitopes .

84 Discussions. The analysis of the tuberculous meningitis isolates and the availability of the

85 variations obtained will provide additional resources for global comparison of isolates from

86 pulmonary tuberculosis and tuberculosis meningitis. It will also contribute to the richness of

87 genomic databases towards the prediction of antibiotic resistance, level of virulence and of origin

88 of infection.

89

90

91 
92

93

94

95

Introduction

96

Tuberculosis (TB) remains a global threat despite efforts targeted towards its control. With

97 recent advances in next generation sequencing, the analysis of bacterial whole genome sequences

has contributed significantly to the understanding of virulence factors and antibiotic resistance of

99 pathogenic bacteria (Koser et al. 2013; Leopold et al. 2014). Currently, there are software tools

100 and databases that are used for predicting bacterial genotype, lineages and drug resistance profile

101 from mycobacterial whole genome sequence data (Benavente et al. 2015; Coll et al. 2015).

102 Availability of more whole genome data (processed and unprocessed), especially from genotypes

103 not currently available, will contribute immensely to the profiling of pathogens.

104 Although tuberculosis is a curable disease, 9.0 million new cases and 1.5 million TB deaths were recorded in 2013 (Zumla et al. 2015). This is due in part to incomplete understanding of the variations that contribute to the pathogenesis and antibiotic resistance of Mycobacterium

107 tuberculosis. There are two broad types of clinical TB disease; pulmonary (PTB) in which the

108 site of infection is the lung and extra-pulmonary, including the more severe tuberculous

109 meningitis (TBM), in which the bacteria cross the blood brain barrier to get into the

110 cerebrospinal fluid (CSF) of the patient. The morbidity and mortality rate of TBM is higher than

111 PTB (Thwaites et al. 2013). The genotype of the infecting mycobacterium has been shown to be

112 one of the factors that contribute to the severity of the disease and can play a role in emergence

113 of drug resistance, susceptibility to TBM, host response and in transmissibility (Ford et al. 2013;

114 Lopez et al. 2003; Nahid et al. 2010; Thwaites et al. 2008). However the genetic factors that 
115 determine the association of different lineages of mycobacteria with different level of disease

116 severity remain largely unknown.

117 There have been controversies in associating specific genotypes with morbidity or mortality from

118 TB. A study in Thailand associated the modern Beijing genotype with a more severe disease

119 progression when compared with other lineages (Faksri et al. 2011). However, in a study

120 conducted in HIV patients in Vietnam, modern Beijing genotype had lower mortality rates than

121 those infected with other lineages (Tho et al. 2012). Comparing strains isolated from TBM across

122 genotypes on a whole genome scale may provide better understanding of factors that contribute

123 to the severity of the disease.

124 IS6110 based restriction fragment length polymorphism (RFLP) is an internationally recognized

125 method for genotyping mycobacteria (Thierry et al. 1990; van Embden et al. 1993). Nonthaburi

126 strains of M. tuberculosis were first identified in Thailand by its IS6110-RFLP patterns, usually

127 containing 9-14 bands. Subsequent spoligotyping revealed that the Nonthaburi type has a

128 spoligotype octal code 674000003413771 specifying the East-Asian India 2 Nonthaburi (EAI2-

129 Nonthaburi) genotype (Palittapongarnpim et al. 1997) [14]. It has been reported in lower

130 percentages from many countries such as the Netherlands, Australia, USA, Sweden, Saudi

131 Arabia, Tunisia, and Taiwan. However, the origin of the isolates is likely to be South East Asia,

132 as more isolates are from countries such as Indonesia, Laos PDR, Vietnam, Cambodia,

133 Philippines and Thailand (Demay et al. 2012).

134 Up to date, only relatively little information is available on the genetic characteristics of the

135 Nonthaburi strains. Three Nonthaburi strains were isolated from the CSF samples of TBM

136 patients at Siriraj Hospital, Mahidol University, Thailand. For a deeper understanding of the

137 characteristics of these isolates, genome-wide scale analysis and drug susceptibility pattern to 
138 anti-tuberculosis drugs were performed and compared to the reference strain M. tuberculosis

139 H37Rv (NC_000962.3). The single nucleotide polymorphism (SNPs) common to the isolates

140 were compared with SNPs from 1,601 genomes from the 7 different lineages and various

141 sublineages of M. tuberculosis complex (MTBC). The whole genome sequence of the isolates

142 were assembled into draft genomes, annotated and have been deposited into NCBI database for

143 public access. Prior to our study, there was no complete or draft genome belonging to the

144 Nonthaburi genotype of M. tuberculosis in the database.

146 Methods

147 Selection of strains

148 Three isolates, CSF3053, 46-5069 and 43-13838, identified to belong to Nonthaburi genotype by

149 IS6110-RFLP, were selected from the stock of samples collected from the CSF of TBM patients

150 at the Drug Resistant Tuberculosis Research Fund laboratory, Department of Microbiology,

151 Faculty of Medicine Siriraj Hospital, Mahidol University, Thailand.

\section{Genomic DNA extraction}

153 Stock culture of selected strains, stored at $-70^{\circ} \mathrm{C}$ in $\mathrm{MH} 79$ broth containing $15 \%$ glycerol, were

154 subcultured on Loewenstein-Jensen medium and incubated for 4 weeks at $37^{\circ} \mathrm{C}$. DNA extraction

155 was carried out using cetyltrimethylammonium bromide (CTAB)-lysozyme enzymatic method

156 as earlier described (Larsen et al. 2007).

\section{Spoligotyping}

158 Spacer oligonucleotide typing, a polymerase chain reaction (PCR) based method used in typing

159 M. tuberculosis was performed following the methods earlier described (Gori et al. 2005). 


\section{Whole genome sequencing and analysis}

163 Genomic DNA samples isolated from the three isolates were sequenced at Macrogen Inc., Seoul,

164 South Korea on the HiSeq 2000 platform with insert size of 300 bp (Illumina, San Diego, CA,

165 USA) yielding $100 \mathrm{bp}$ paired end reads. The qualities of the sequences were assessed with

166 FastQC software (www.bioinformatics.babraham.ac.uk/projects/fastqc) to determine the

167 parameters used for trimming. Bases with quality of less than 5, reads with average of quality

168 less than 20 for every four bases, and reads with lengths that are less than 45 bases were

169 discarded using Trimmomatic software (Bolger et al. 2014) (version 0.33). The trimmed

170 sequences were aligned to the reference strain M. tuberculosis H37Rv (NC_000962.3) using the

171 short reads aligner, Bowtie2 (version 2.2.0) (Langmead et al. 2012). The genomic coverage was

172 estimated using Bedtools (version 2.18) (Quinlan et al. 2010). The fold coverage is estimated as

173 the number of reads supporting a particular nucleotide position on the genome. Variant calling

174 was performed on the aligned sequences using the Genome Analysis Tool Kit (GATK) (version

175 3.3) haplotype caller (McKenna et al. 2010) with minimum calling confidence threshold set at

176 phred score 30. Point allelic variation at any position within the genome when compared with the

177 reference $\mathrm{H} 37 \mathrm{Rv}$ genome (NC_000962.3) is considered a single nucleotide polymorphism

178 (SNP).

179 SnpEFF (Cingolani et al. 2012) (version 4.0) software was used to annotate the SNPs. The

180 SNPs were filtered using standard hard filtering parameters according to GATK Best Practices

181 Recommendations (DePristo et al. 2011, Van der Auwera et al. 2013). Variants with

182 QualByDepth $<2.0$, FisherStrand $>60$, RMSMapping quality $<40$,

183 MappingQualityRankSumTest $<-12.5$ and ReadPosRankSumTest $<-8$ were filtered. All SNPs 
184 were confirmed using Integrated Genomic Viewer (IGV) (James et al. 2011) (version 2.0). The

185 SNPs were further grouped according to the functions of the genes in which they were found in

186 the genome when compared to the reference genome H37Rv (NC_000962.3). We evaluated

187 SNPs in groups of genes considered to be essential, drug resistance related, virulence related,

188 contain known epitopes and associated with efflux pumps.

189 The Whole Genome Shotgun project has been deposited at DDBJ/EMBL/GenBank under the 190 accession numbers LGCH00000000, LGCG00000000 and LGCF00000000. The versions

191 described in this paper are LGCH01000000, LGCG01000000 and LGCF01000000 for CSF3053,

192 46-5069 and 43-13838 respectively. The raw sequences have been deposited to the short read

193 archive (SRA) of NCBI under accession numbers SRX1094547, SRX1094546 and SRX1094545

194 for isolates CSF3053, 46-5069 and 43-13838 respectively.

196 Determination of principle genetic group, lineage and sequence type

197 Nucleotide alleles at positions 7585 and 2154724 were investigated to determine the principal

198 genetic group of the isolates as earlier defined (Sreevatsan et al. 1997). To determine the lineage

199 of the isolates, SNPs specific to different lineages as earlier reported (Coll et al. 2014b) were

200 investigated.

201 Draft genome assembly:

202 The paired-end raw reads of the isolates were assembled into draft genomes by using the de novo 203 assembly algorithm of CLC Genomics Workbench (version 7.5) which works by using a de 204 Bruijn graph (http://www.clcbio.com). The minimum contig output was set at $200 \mathrm{bp}$ long. 205 Annotation of the draft genome was performed by Rapid Annotation using Subsystem 
206 Technology (RAST) (http://www.nmpdr.org/) and by NCBI Prokaryotic Genome Annotation

207 Pipeline (PGAP) (http://www.ncbi.nlm.nih.gov/genome/annotation_prok/).

208

209 Comparison of Nonthaburi isolates with isolates from other lineages

210 The SNPs that are common to the three isolates were compared with 92,000 SNPs from 1,601

211 genomes of MTBC previously reported (Coll et al. 2014a)

212 (http://pathogenseq.1shtm.ac.uk/phytblive/index.php). These include 121, 390, 189, 856, 17, 11,

213 and 6 genomes from lineages 1, 2, 3, 4, 5, 6, and 7 respectively. Eleven samples from M. bovis

214 were also included.

215 Large sequence polymorphism determination

216 Regions of differences when compared with reference strain H37Rv (NC_000926.3) were

217 determined by using the indel and structural variants determination tool of CLC Genomics

218 Workbench (version 7.5) (http://www.clcbio.com) and Bedtools (version 2.18) (Quinlan et al.

219 2010). The regions of deletions were confirmed with PCR using primers CF

220 (CATCCGCACCGAACCTGTAA) and CR (AACCGTTCACGACAAGCAAC), AF

221 (GCCCAACCTGATTGGTTTCG) and AR (CAAACGCTCGCCATGATCTC), BF

222 (TCGACTGCCATACAACCTGC) and BR (ACTTCCGGTGGTAACAGTGC) respectively for

223 RD239, RD147c and newly identified deletion of 500 bp between 3501224-3501724 (M.

224 tuberculosis $\mathrm{H} 37 \mathrm{Rv}$ (NC_000962.3 genome numbering). The reactions were performed with

225 initial denaturation at $94{ }^{\circ} \mathrm{C}$ and 30 cycles of denaturation for 1 minute, annealing of primers at

$22660^{\circ} \mathrm{C}$ for 1 minute and extension with platinum Taq DNA polymerase for 1 minute at $68^{\circ} \mathrm{C}$.

227 Final extensions were performed at $68^{\circ} \mathrm{C}$ for 10 minutes. The reactions were performed as

228 recommended by the manufacturer of the DNA polymerase. 
230 Drug susceptibility testing

231 The susceptibility of the isolates to first line drugs and other second-line anti-tuberculosis drugs

232 was investigated using the standard agar proportion method (Larsen et al. 2007). The drug

233 concentrations used in the test comprise $0.2 \mathrm{mg} / 1$ isoniazid, $1.0 \mathrm{mg} / 1$ rifampicin, $2.0 \mathrm{mg} / 1$

234 streptomycin, $5.0 \mathrm{mg} / 1$ ethambutol, $1.0 \mathrm{mg} / 1$ linezolid, $6.0 \mathrm{mg} / 1$ amikacin, $5.0 \mathrm{mg} / \mathrm{l}$ ethionamide,

$2352.0 \mathrm{mg} / 1$ paraaminosalycic acid, $2.0 \mathrm{mg} / \mathrm{ml}$ ofloxacin, $2.0 \mathrm{mg} / 1 \mathrm{moxifloxacin}, 2.0 \mathrm{mg} / \mathrm{l}$

236 gatifloxacin, $1.0 \mathrm{mg} / \mathrm{ml}$ sitafloxacin, $6.0 \mathrm{mg} / 1 \mathrm{kanamycin}, 2.0 \mathrm{mg} / 1 \mathrm{ciprofloxacin,} 2.0 \mathrm{mg} / 1$

237 levofloxacin, and $3.0 \mathrm{mg} / \mathrm{l}$ clarithromycin. Growth equal to or more than $1 \%$ on drug containing

238 media compared to drug free media was recorded as drug resistance. The phenotypic drug testing

239 was performed on the initial isolates from the patients and repeated on the stock cultures.

240 Ethical Approval

241 The study was approved by the Institutional review board (IRB) of Faculty of Medicine Siriraj

242 Hospital, Mahidol University SiEC No. 152/2549

243

244 Results and discussion

245 For the three isolates CSF3053, 46-5069 and 43-13838, an average of $99.1 \%$ of raw reads

246 mapped to the reference genome. On the average, $99.8 \%$ of the reference was covered to at least

247 1-fold coverage. The depth across all the positions covered by the reads was about 1,056-fold on 248 the average, Table 1. 


\section{Genome assembly}

253 The sequences of the isolates were assembled and annotated as described in Methods. 159

254 contigs with $N_{50}$ of $69,028,173$ contigs with $N_{50}$ of 63,852 , and 177 contigs with $N_{50}$ of 63,019

255 contigs were obtained for CSF3053, 43-5069 and 46-13838 respectively. All isolates have 65.5

$256 \%$ guanine/cytosine (GC) content, typical of mycobacteria. The draft genomes have an average

257 size of 4,364,461 bp, 4,154 genes, 48 rRNAs and 64 pseudogenes. Details of the assembly and

258 annotation are shown in Table 1.

260 Single nucleotide polymorphisms

261 Point allelic variations at any position within the genome when compared with the reference

262 H37Rv genome (NC_000962.3) were investigated.

263 In total, 2,202 positions were found to have similar allelic changes (SNPs) in all isolates as

264 shown in Figure 1. 1,963 are in coding regions (754 synonymous, 1209 (61.6\%) non

265 synonymous) and 239 are intergenic. In this study, CSF3053, 46-5069 and 43-13838 have 10, 7

266 and 49 unique SNPs respectively. 43-13838 and CSF3053 have 23 SNPs in common, CSF3053

267 and 46-5069 have 99 SNPs in common, while 43-13838 and 46-5069 have 7 SNPs in common.

268 Using the SNPs, the isolates were found to belong to lineage 1 with the presence of allele C/A

269 and $\mathrm{G} / \mathrm{C}$ at positions 2154724 and 7585 resulting in kat $G \mathrm{R} 463 \mathrm{~L}$ and gyr $A$ S95T respectively

270 (Sreevatsan et al. 1997). Using a recently developed SNP barcode (Coll et al. 2014a), the isolates

271 were found to be specific to Indo Oceanic lineage 1.2.1, with nucleotide changes G/A at position

272 615938, C/A at position 3479545, G/C at position 4244420 and $\mathrm{G} / \mathrm{C}$ at position 9260.

273 The 2,202 SNPs that were found to be common to the isolates in this study were compared with

27492,000 SNPs from 1,601 genomes of MTBC that were analyzed previously. These include 121, 
$275390,189,856,17,11$, and 6 genomes from lineages 1, 2, 3, 4, 5, 6, and 7, respectively. Eleven

276 samples from M. bovis were also included (Coll et al. 2014a). The common SNPs were used to

277 position the strains on a phylogenetic tree compared to other strains and lineages of MTBC as

278 shown in figure S1. Nucleotide change G/C at position 2342203 was found only in the isolates in

279 this study when compared with the 1,601 MTBC genomes. There is evidence from macrophage

280 systems that strain-to-strain variability affects phenotypic outcomes (McEvoy et al. 2012).

281 Phylogeographic strain variation may therefore have considerable effect on the development of

282 new diagnostic tools, vaccines and drugs.

$283 \mathrm{SNP}$ C/T at position 3378828 was reported to be unique to members of lineage 1 (Coll et al.

284 2014a). Although this SNP was found in many genomes belonging to lineage 1, we found out

285 that it was absent in the three isolates in this study and in 6 other Nonthaburi isolates from

286 Thailand and the Netherlands used in previous studies which are grouped under lineage 1 . This

287 indicates that the allele change at this position may be specific only to a sub-branch of lineage 1.

288 Synonymous SNP T/C at position 28910, non-synonymous SNP C/T at position 152178

289 resulting in Thr344Ile in pepA gene and intergenic SNP C/T at position 1180580 were found

290 only in Nonthaburi isolates from Thailand. They were not found in any genome belonging to

291 lineages 2, 3, 4, 5, 6 and 7. Within lineage 1, these SNPs were found only in Thai Nonthaburi

292 isolates, from previous study (Coll et al. 2014a), and the isolates in this study. They were

293 however absent in the Nonthaburi genotype isolates from the Netherlands. pepA gene is a

294 probable serine protease with the exact function unknown. It is in the intermediary metabolism

295 and respiration functional category. Its mRNA was found to be upregulated after 96 hours of

296 starvation (Betts et al. 2002), suggesting its role in the adaptation of mycobacteria to extreme 
297 conditions. The association of the SNPs at these positions with Thailand warrants further

298 investigation.

299

300

301 Large sequence polymorphism

302 Region of difference RD239 that is specific to lineage 1 of MTBC and previously reported

$303 \mathrm{RD} 147 \mathrm{c}$, not specific to lineage 1, were found in all the three isolates. In addition, a region of

304 deletion of 500 bp between 3501224-3501724 (M. tuberculosis H37Rv (NC_000962.3 genome

305 numbering) comprising Rv3135 (ppe50), was observed in all isolates. The details of the deletions

306 as well as the affected open reading frames are shown in Table 2. The deletions were confirmed

307 with PCR (see Figures S2, S3 and S4). The PE-PPE protein class, while not well characterized,

308 represents the third most abundant category of mycobacterial proteins and showed the most

309 consistent expression during infection (Kruh et al. 2010). Although PPE50 has a yet unknown

310 function, it was listed among promising therapeutic target in tuberculosis treatment based on its

311 expression, and homology to human and other microbial proteins (Raman et al. 2008). The

312 deletion of this gene may be a means of evading recognition by the host immune system.

313 Deletions have been shown to have a wide range of effects on $M$. tuberculosis including

314 association with an increased probability of transmission (Tsolaki et al. 2004).

316 Polymorphisms in drug resistance associated genes

317 Despite being isolated from patients with severe form of tuberculosis, drug susceptibility tests

318 results show that the three isolates are susceptible to first line drugs; isoniazid, rifampicin, 
319 ethambutol and streptomycin, and to quinolones: ciprofloxacin, ofloxacin, gatifloxacin,

320 moxifloxacin, levofloxacin, and sitafloxacin. They were also found to be susceptible to linezolid,

321 amikacin, ethionamide, paraaminosalicylic acid, kanamycin and clarithromycin.

322 However, 37 SNPs were found in drug resistant related genes reported in TBdream database and

323 other earlier published reports (Sandgren et al. 2009). Nineteen are synonymous while 18 are non

324 synonymous. Non synonymous mutations Gly312Ser of kas $A$ gene and Ile73Thr in efp $A$ were

325 previously reported to be associated with isoniazid resistance (Mdluli et al. 1998; Ramaswamy et

326 al. 2003), but were found in our isolates. Association between these mutations and resistance to

327 isoniazid needs to be confirmed. iniA gene and Rv1592c were reported to be associated with

328 tolerance to isoniazid (Colangeli et al. 2005; Ramaswamy et al. 2003). In our analysis, mutations

329 His481Gln in iniA gene and Ile322Val in Rv1592c were found. These positions may not be

330 associated with the supposed roles of these genes in isoniazid resistance.

331 Polymorphism exists at position 237 of nudC in M. tuberculosis isolates (Wang et al. 2011). In

332 particular, the amino acid change Gln237Pro in $n u d C$ is found in the Indo Oceanic and West

333 African lineages. It was demonstrated to prevent dimer formation and results in the loss of

334 activity of the enzyme. It was also shown to degrade the active forms of isoniazid and

335 ethionamide (Wang et al. 2011). We however found this codon change in all isolates in this

336 study. This suggests the non-involvement of the amino acid change at this position in resistance

337 to both drugs.

338 Mutations Cys110Tyr in embR, Thr270Ile and Asn394Asp in embC, Pro913Ser in $e m b A$ and

339 Glu378Ala in $e m b B$, were previously reported to be involved in ethambutol resistance

340 (Ramaswamy et al. 2000; Srivastava et al. 2009). However, these mutations were found in this

341 study. Mutation Ser257Pro in $r m l D$ was suspected to be involved in isoniazid and ethambutol 
342 resistance (Ramaswamy et al. 2000). This was however found in all isolates considered in this

343 study. Mutations Glu21Gln in gyrA, Ile322Val in Rv1592c, Arg463Leu in katG, and Arg93Leu

344 in $c y c A$ were found to be common to the isolates in this study. They have also been reported to

345 be common to pan-susceptible and drug resistant $M$. tuberculosis sequence type 10 Beijing

346 isolates (Regmi et al. 2015). Our results confirm that these mutations are polymorphic rather than

347 being involved in drug resistance. The details of the synonymous and non-synonymous SNPs

348 found in drug resistant related genes and the predicted protein variation effects are shown in

349 Table 3.

350

351 Polymorphisms in virulence genes, efflux pump related genes, and essential genes

352 Oftentimes, mutations provide selective advantage to an organism in a particular environment.

353 Some non-synonymous mutations in $r p o C$ gene have been shown to result in higher

354 competitiveness in vitro and have higher fitness in vivo evidenced by their prevalence across

355 patient populations (Comas et al. 2012). In this study, we found Ala172Val mutation in rpoC

356 gene in all isolates.

357 We also sought to determine polymorphisms in genes that play important roles in the survival 358 and pathogenesis of M. tuberculosis. Of particular interest are the genes that are involved in the

359 evasion of the host immune system. SNPs in 37 mycobacteria virulence related genes were found

360 to be common to the isolates. Twenty nine of the SNPs are non-synonymous. Polyketide

361 synthases (PKs) are group of genes involved in the synthesis of polyketides which are

362 structurally complex compounds produced by organisms for survival advantage. Some

363 mycobacteria PKs genes such as $p k s 15, p k s 1, p k s 10, p k s 12, p k s 5$, and $p k s 7$ are known to be

364 involved in virulence (Reed et al. 2004; Rousseau et al. 2003; Sirakova et al. 2003; Tsenova et 
365 al. 2005). Insertion of 7 base pairs was found in $p k s 15 / 1$ junction in all isolates. The presence of

366 the 7 base pair insertion leads to a frame shift that results in the loss of stop codon of pks 15 . This

367 results in a continuous transcription of $p k s 15$ and $p k s 1$. This was previously associated with the

368 more virulent phenotype of the modern Beijing family, but such claim has since been refuted as

369 it can be found across the seven lineages. The implication of the insertion needs further

370 experiments to understand. Two mutations Ile474Met and Thr604Ala were found in $n u o G$ gene.

$371 n u o G$ is a probable NADH dehydrogenase, reported to be involved in apoptosis inhibition

372 (Velmurugan et al. 2007). Mutation Arg463Leu was found in $k a t G$, a gene previously implicated

373 in inhibiting antimicrobial effectors of the macrophage ( $\mathrm{Ng}$ et al. 2004). Protein kinases such as

$374 p k n D$ and $p k n G$ are important virulent factors of M. tuberculosis. pknD has been reported to play

375 a role in the infection of the host's central nervous system by M. tuberculosis (Be et al. 2012;

376 Cowley et al. 2004). Gln472Pro mutation in $p k n D$ was found in all isolates. virS is a

377 transcription regulator that belongs to AraC family. Its attenuation in a mouse model resulted in

378 an increased animal survival (Gupta et al. 1999; Singh et al. 2003). We found mutation

379 Leu316Arg in this gene in all isolates.

380 Stop codon was gained after Arg305 in PStA1, an inorganic phosphate ABC transporter. Stop

381 codon was however lost in $R v 1504$. The stop codon was replaced with glutamine as codon 200.

$382 R v 1504$ and PstAl were reported to be involved in the adaptation and survival of mycobacteria in 383 macrophages (Brodin et al. 2010; Rengarajan et al. 2005).

384 Non-synonymous and synonymous SNPs were found in other genes involved in various other

385 functions related to virulence such as synthesis of complex and simple lipids, cell wall proteins,

386 lipoproteins, cholesterol metabolism, secretion systems, protein kinases, metal transporter

387 proteins, two component systems and other proteins of unknown functions (Table S1). 
388 Efflux pumps play roles in drug resistance, cell physiology, detoxification and virulence of $M$.

389 tuberculosis (Nikaido 2009). Ten synonymous SNPs and 15 non-synonymous SNPs were found

390 in efflux pump related genes. One stop codon was gained by $R v 2994$, a predicted transmembrane

391 protein involved in efflux system (Table S2).

392

393 Twenty eight SNPs were observed in genes with known epitopes, 11 are synonymous while 17

394 are non-synonymous (Table S3).

395 In addition, 316 SNPs were found in essential genes, 135 are synonymous, 181 are non-

396 synonymous. A start codon was lost in $p a b B$ gene. $p a b B$ is a cell membrane associated gene that

397 encodes para-aminobenzoate synthetase component-I involved in the biosynthesis of $p$ -

398 aminobenzoate, a precursor of folate biosynthesis (Sassetti et al. 2003; Zheng et al. 2008). The

399 details of the position, nucleotide change, amino acid change and the genes involved are

400 presented in Table S4.

401 The association of the SNPs or deletions reported in this study to TBM needs further

402 investigations. This can be done by comparing them with variations from PTB cases, to

403 determine exclusive associations with TBM. Furthermore, The involvement of the reported

404 allelic changes in the functions of the various genes from which they were found can be verified

405 by site directed mutagenesis in laboratory strains of $M$. tuberculosis, and subsequent animal 406 experiments.

407 Conclusion

408 Genetic factors that contribute to the ability of infecting mycobacteria in causing TBM remain

409 largely unknown. We have presented a detailed analysis of the polymorphism existing in the

410 genome of Nonthaburi isolates from TBM patients, when compared to reference strain $M$. 
411 tuberculosis $\mathrm{H} 37 \mathrm{Rv}$ (NC_000962.3). The polymorphisms were compared to 1,601 genomes

412 representing the members of the 7 MTBC lineages. Uniqueness of certain SNPs to certain

413 genotypes, countries or region such as found in this study may be useful epidemiologically to

414 determine the origin of an infection and potential level of disease severity. We have also

415 presented the first draft genomes of M. tuberculosis Nonthaburi genotype.

416 Many studies have reported the SNPs playing roles in drug resistance in many drug resistant

417 related genes. These have majorly formed the basis for the development of some databases. It is

418 equally important to report polymorphisms found in these genes from drug susceptible strains so

419 that SNPs that are not involved in resistance to drugs but present in the drug resistance related

420 genes could be filtered out in the process of predicting drug resistance. Our results will also form

421 a basis for comparison with other genotypes of mycobacteria isolated from the CSF of TBM or

422 sputum of PTB patients in order to identify potential factors contributing to TBM.

423

424 Supplementary Information:

425 Supplementary Figures S2, S3, S4

426 Supplementary Tables S1, S2

427 Supplementary Table S3

428 Supplementary Table S4

429

430

431

432 References 
433

434

435

436

437

438

439

440

441

442

443

444

445

446

447

448

449

450

451

452.

453

454

455

456

457

458

459

460

461

462

463

464

465

466

467

468

469

470

471

472

473

474

475

476

477

Be NA, Bishai WR, and Jain SK. 2012. Role of Mycobacterium tuberculosis pknD in the pathogenesis of central nervous system tuberculosis. BMC Microbiology 12:7. 10.1186/1471-2180-12-7

Benavente ED, Coll F, Furnham N, McNerney R, Glynn JR, Campino S, Pain A, Mohareb FR, and Clark TG. 2015. PhyTB: Phylogenetic tree visualisation and sample positioning for M. tuberculosis. BMC Bioinformatics 16:155. 10.1186/s12859-015-0603-3

Betts JC, Lukey PT, Robb LC, McAdam RA, and Duncan K. 2002. Evaluation of a nutrient starvation model of Mycobacterium tuberculosis persistence by gene and protein expression profiling. Molecular Microbiology 43:717-731.

Bolger AM, Lohse M and Usadel B. 2014. Trimmomatic: A flexible trimmer for Illumina

Sequence Data. Bioinformatics, btu170

Brodin P, Poquet Y, Levillain F, Peguillet I, Larrouy-Maumus G, Gilleron M, Ewann F, Christophe T, Fenistein D, Jang J, Jang MS, Park SJ, Rauzier J, Carralot JP, Shrimpton R, Genovesio A, Gonzalo-Asensio JA, Puzo G, Martin C, Brosch R, Stewart GR, Gicquel $B$, and Neyrolles 0. 2010. High content phenotypic cell-based visual screen identifies Mycobacterium tuberculosis acyltrehalose-containing glycolipids involved in phagosome remodeling. PLoS Pathogens 6:e1001100. 10.1371/journal.ppat.1001100

Choi Y, Sims GE, Murphy S, Miller JR and Chan AP. 2012. Predicting the Functional Effect of Amino Acid Substitutions and Indels. PLoS ONE 7(10): e46688

Cingolani P, Platts A, Wang le L, Coon M, Nguyen T, Wang L, Land SJ, Lu X and Ruden DM. 2012. A program for annotating and predicting the effects of single nucleotide polymorphisms, SnpEff: SNPs in the genome of Drosophila melanogaster strain w1118; iso-2; iso-3. Fly 6(2):80-92.

Colangeli R, Helb D, Sridharan S, Sun J, Varma-Basil M, Hazbon MH, Harbacheuski R, Megjugorac NJ, Jacobs WR, Jr., Holzenburg A, Sacchettini JC, and Alland D. 2005. The Mycobacterium tuberculosis iniA gene is essential for activity of an efflux pump that confers drug tolerance to both isoniazid and ethambutol. Molecular Microbiology 55:1829-1840. 10.1111/j.1365-2958.2005.04510.x

Coll F, McNerney R, Guerra-Assuncao JA, Glynn JR, Perdigao J, Viveiros M, Portugal I, Pain A, Martin N, and Clark TG. 2014a. A robust SNP barcode for typing Mycobacterium tuberculosis complex strains. Nature Communications 5:4812. $10.1038 /$ ncomms5812

Coll F, McNerney R, Preston MD, Guerra-Assuncao JA, Warry A, Hill-Cawthorne G, Mallard K, Nair M, Miranda A, Alves A, Perdigao J, Viveiros M, Portugal I, Hasan Z, Hasan R, Glynn JR, Martin N, Pain A, and Clark TG. 2015. Rapid determination of antituberculosis drug resistance from whole-genome sequences. Genome Medicine 7:51. 10.1186/s13073-015-0164-0

Coll F, Preston M, Guerra-Assuncao JA, Hill-Cawthorn G, Harris D, Perdigao J, Viveiros M, Portugal I, Drobniewski F, Gagneux S, Glynn JR, Pain A, Parkhill J, McNerney R, Martin N, and Clark TG. 2014b. PolyTB: a genomic variation map for Mycobacterium tuberculosis. Tuberculosis 94:346-354. 10.1016/j.tube.2014.02.005

PeerJ reviewing PDF | (2015:11:7693:1:1:CHECK 3 Mar 2016) 
478

479

480

481

482

483

484

485

486

487

488

489

490

491

492

493

494

495

496

497

498

499

500

501

502

503

504

505

506

507

508

509

510

511

512

513

514

515

516

517

518

519

520

521

522

Comas I, Borrell S, Roetzer A, Rose G, Malla B, Kato-Maeda M, Galagan J, Niemann S, and Gagneux S. 2012. Whole-genome sequencing of rifampicin-resistant Mycobacterium tuberculosis strains identifies compensatory mutations in RNA polymerase genes. Nature Genetics 44:106-110. 10.1038/ng.1038.

Cowley S, Ko M, Pick N, Chow R, Downing KJ, Gordhan BG, Betts JC, Mizrahi V, Smith DA, Stokes RW, and Av-Gay Y. 2004. The Mycobacterium tuberculosis protein serine/threonine kinase PknG is linked to cellular glutamate/glutamine levels and is important for growth in vivo. Molecular Microbiology 52:1691-1702. 10.1111/j.1365-2958.2004.04085.x

DePristo M, Banks E, Poplin R, Garimella K, Maguire J, Hartl C, Philippakis A, del Angel G, Rivas MA, Hanna M, McKenna A, Fennell T, Kernytsky A, Sivachenko A, Cibulskis K, Gabriel S, Altshuler D and Daly M. 2011. A framework for variation discovery and genotyping using next-generation DNA sequencing data. Nature Genetics 43:491-498

Demay C, Liens B, Burguiere T, Hill V, Couvin D, Millet J, Mokrousov I, Sola C, Zozio T, and Rastogi N. 2012. SITVITWEB--a publicly available international multimarker database for studying Mycobacterium tuberculosis genetic diversity and molecular epidemiology. Infection, genetics and evolution : Journal of Molecular Epidemiology and Evolutionary Genetics in Infectious Diseases 12:755-766. 10.1016/j.meegid.2012.02.004

Faksri K, Drobniewski F, Nikolayevskyy V, Brown T, Prammananan T, Palittapongarnpim P, Prayoonwiwat N, and Chaiprasert A. 2011. Epidemiological trends and clinical comparisons of Mycobacterium tuberculosis lineages in Thai TB meningitis. Tuberculosis 91:594-600. 10.1016/j.tube.2011.08.005

Ford CB, Shah RR, Maeda MK, Gagneux S, Murray MB, Cohen T, Johnston JC, Gardy J, Lipsitch M, and Fortune SM. 2013. Mycobacterium tuberculosis mutation rate estimates from different lineages predict substantial differences in the emergence of drug-resistant tuberculosis. Nature Genetics 45:784-790. 10.1038/ng.2656

Gori A, Bandera A, Marchetti G, Degli Esposti A, Catozzi L, Nardi GP, Gazzola L, Ferrario G, van Embden JD, van Soolingen D, Moroni M, and Franzetti F. 2005. Spoligotyping and Mycobacterium tuberculosis. Emerging Infectious Diseases 11:1242-1248. 10.3201/eid1108.040982.

Guillemin I, Jarlier V, and Cambau E. 1998. Correlation between Quinolone Susceptibility Patterns and Sequences in the A and B Subunits of DNA Gyrase in Mycobacteria. Antimicrobial Agents and Chemotherapy 42:2084-2088

Gupta S, Jain S, and Tyagi AK. 1999. Analysis, expression and prevalence of the Mycobacterium tuberculosis homolog of bacterial virulence regulating proteins. FEMS Microbiology Letters 172:137-143

Heym B, Alzari PM, Honore N, and Cole ST. 1995. Missense mutations in the catalaseperoxidase gene, katG, are associated with isoniazid resistance in Mycobacterium tuberculosis. Molecular Microbiology 15:235-245

James TR, Helga T, Wendy W, Mitchell G, Eric SL ,Gad G, and Jill PM. 2011. 
523

524

525

526

527

528

529

530

531

532

533

534

535

536

537

538

539

540

541

542

543

544

545

546

547

548

549

550

551

552

553

554

555

556

557

558

559

560

561

562

563

564

565

566

567

568

Integrative Genomics Viewer. Nature Biotechnology. 29, 24-26.

Kapur V, Li LL, Hamrick MR, Plikaytis BB, Shinnick TM, Telenti A, Jacobs WR, Jr., Banerjee A, Cole $S$ and Yuen KY. 1995. Rapid Mycobacterium species assignment and unambiguous identification of mutations associated with antimicrobial resistance in Mycobacterium tuberculosis by automated DNA sequencing. Archives of Pathology \& Laboratory Medicine 119:131-138

Koser CU, Bryant JM, Becq J, Torok ME, Ellington MJ, Marti-Renom MA, Carmichael AJ, Parkhill J, Smith GP, and Peacock SJ. 2013. Whole-genome sequencing for rapid susceptibility testing of $M$. tuberculosis. The New England Journal of Medicine 369:290-292. 10.1056/NEJMc1215305.

Kruh NA, Troudt J, Izzo A, Prenni J, and Dobos KM. 2010. Portrait of a pathogen: the Mycobacterium tuberculosis proteome in vivo. PloS One 5:e13938.

10.1371/journal.pone.0013938

Langmead B and Salzberg S. 2012. Fast gapped-read alignment with Bowtie 2. Nature Methods. 9:357-359

Larsen MH, Biermann K, Tandberg S, Hsu T, and Jacobs WR, Jr. 2007. Genetic Manipulation of Mycobacterium tuberculosis. Curr Protoc Microbiol Chapter 10:Unit 10A 12. 10.1002/9780471729259.mc10a02s6

Lavender C, Globan M, Sievers A, Billman-Jacobe H, and Fyfe J. 2005. Molecular characterization of isoniazid-resistant Mycobacterium tuberculosis isolates collected in Australia. Antimicrobial Agents and Chemotherapy 49:4068-4074. 10.1128/AAC.49.10.4068-4074.2005

Lee AS, Lim IH, Tang LL, Telenti A, and Wong SY. 1999. Contribution of kasA analysis to detection of isoniazid-resistant Mycobacterium tuberculosis in Singapore. Antimicrobial Agents and Chemotherapy 43:2087-2089

Leopold SR, Goering RV, Witten A, Harmsen D, and Mellmann A. 2014. Bacterial wholegenome sequencing revisited: portable, scalable, and standardized analysis for typing and detection of virulence and antibiotic resistance genes. Journal of Clinical Microbiology 52:2365-2370. 10.1128/JCM.00262-14

Lopez B, Aguilar D, Orozco H, Burger M, Espitia C, Ritacco V, Barrera L, Kremer K, Hernandez-Pando R, Huygen K, and van Soolingen D. 2003. A marked difference in pathogenesis and immune response induced by different Mycobacterium tuberculosis genotypes. Clinical and Experimental Immunology 133:30-37

Mathys V, Wintjens R, Lefevre P, Bertout J, Singhal A, Kiass M, Kurepina N, Wang XM, Mathema B, Baulard A, Kreiswirth BN, and Bifani P. 2009. Molecular genetics of para-aminosalicylic acid resistance in clinical isolates and spontaneous mutants of Mycobacterium tuberculosis. Antimicrobial Agents and Chemotherapy 53:2100-2109. 10.1128/AAC.01197-08

McEvoy CR, Cloete R, Muller B, Schurch AC, van Helden PD, Gagneux S, Warren RM, and Gey van Pittius NC. 2012. Comparative analysis of Mycobacterium tuberculosis pe and ppe genes reveals high sequence variation and an apparent absence of selective constraints. PloS One 7:e30593. 10.1371/journal.pone.0030593 
569

570

571

572

573

574

575

576

577

578

579

580

581

582

583

584

585

586

587

588

589

590

591

592

593

594

595

596

597

598

599

600

601

602

603

604

605

606

607

608

609

610
McKenna A, Hanna M, Banks E, Sivachenko A, Cibulskis K, Kernytsky A, Garimella K, Altshuler D, Gabriel S, Daly M and DePristo MA. 2010. The Genome Analysis Toolkit: a MapReduce framework for analyzing next-generation DNA sequencing data. Genome Research 20:1297-303

Mdluli K, Slayden RA, Zhu Y, Ramaswamy S, Pan X, Mead D, Crane DD, Musser JM, and Barry CE, 3rd. 1998. Inhibition of a Mycobacterium tuberculosis beta-ketoacyl ACP synthase by isoniazid. Science 280:1607-1610.

Nahid P, Bliven EE, Kim EY, Mac Kenzie WR, Stout JE, Diem L, Johnson JL, Gagneux S, Hopewell PC, Kato-Maeda M, and Tuberculosis Trials C. 2010. Influence of $M$. tuberculosis lineage variability within a clinical trial for pulmonary tuberculosis. PloS One 5:e10753. 10.1371/journal.pone.0010753

Ng VH, Cox JS, Sousa AO, MacMicking JD, and McKinney JD. 2004. Role of KatG catalaseperoxidase in mycobacterial pathogenesis: countering the phagocyte oxidative burst. Molecular Microbiology 52:1291-1302. 10.1111/j.1365-2958.2004.04078.x Nikaido H. 2009. Multidrug resistance in bacteria. Annual Review of Biochemistry 78:119146. 10.1146/annurev.biochem.78.082907.145923

Okamoto S, Tamaru A, Nakajima C, Nishimura K, Tanaka Y, Tokuyama S, Suzuki Y, and Ochi K. 2007. Loss of a conserved 7-methylguanosine modification in 16S rRNA confers low-level streptomycin resistance in bacteria. Molecular Microbiology 63:10961106. 10.1111/j.1365-2958.2006.05585.x

Palittapongarnpim P, Luangsook P, Tansuphaswadikul S, Chuchottaworn C, Prachaktam R, and Sathapatayavongs B. 1997. Restriction fragment length polymorphism study of Mycobacterium tuberculosis in Thailand using IS6110 as probe. The International Journal of Tuberculosis and Lung Disease : the Official Journal of the International Union Against Tuberculosis and Lung Disease 1:370-376

Projahn M, Koser CU, Homolka S, Summers DK, Archer JA, and Niemann S. 2011. Polymorphisms in isoniazid and prothionamide resistance genes of the Mycobacterium tuberculosis complex. Antimicrobial Agents and Chemotherapy 55:4408-4411. 10.1128/AAC.00555-11

Quinlan AR and Hall IM. 2010. BEDTools: a flexible suite of utilities for comparing genomic features. Bioinformatics. 26, 6, pp. 841-842

Raman K, Yeturu K, and Chandra N. 2008. targetTB: a target identification pipeline for Mycobacterium tuberculosis through an interactome, reactome and genome-scale structural analysis. BMC Systems Biology 2:109. 10.1186/1752-0509-2-109

Ramaswamy SV, Amin AG, Goksel S, Stager CE, Dou SJ, El Sahly H, Moghazeh SL, Kreiswirth BN, and Musser JM. 2000. Molecular genetic analysis of nucleotide polymorphisms associated with ethambutol resistance in human isolates of Mycobacterium tuberculosis. Antimicrobial Agents and Chemotherapy 44:326-336. 
611 Ramaswamy SV, Reich R, Dou SJ, Jasperse L, Pan X, Wanger A, Quitugua T, and Graviss EA.

612

613

614

615

616

617

618

619

620

621

622

623

624

625

626

627

628

629

630

631

632

633

634

635

636

637

638

639

640

641

642

643

644

645

646

647

648

649

650

651

652

653

654

655
2003. Single nucleotide polymorphisms in genes associated with isoniazid resistance in Mycobacterium tuberculosis. Antimicrobial Agents and Chemotherapy 47:1241-1250.

Reed MB, Domenech P, Manca C, Su H, Barczak AK, Kreiswirth BN, Kaplan G, and Barry CE, 3rd. 2004. A glycolipid of hypervirulent tuberculosis strains that inhibits the innate immune response. Nature 431:84-87. 10.1038/nature02837

Regmi SM, Coker 00, Kulawonganunchai S, Tongsima S, Prammananan T, Viratyosin W, Thaipisuttikul I, and Chaiprasert A. 2015. Polymorphisms in drug-resistant-related genes shared among drug-resistant and pan-susceptible strains of sequence type 10, Beijing family of Mycobacterium tuberculosis. International Journal of Mycobacteriology 4:67-72. http://dx.doi.org/10.1016/j.ijmyco.2014.11.050

Rengarajan J, Bloom BR, and Rubin EJ. 2005. Genome-wide requirements for Mycobacterium tuberculosis adaptation and survival in macrophages. Proceedings of the National Academy of Sciences of the United States of America 102:8327-8332. 10.1073/pnas.0503272102

Rousseau C, Sirakova TD, Dubey VS, Bordat Y, Kolattukudy PE, Gicquel B, and Jackson M. 2003. Virulence attenuation of two Mas-like polyketide synthase mutants of Mycobacterium tuberculosis. Microbiology 149:1837-1847

Sandgren A, Strong M, Muthukrishnan P, Weiner BK, Church GM and Murray MB. 2009. Tuberculosis Drug Resistance Mutation Database. PLoS Medicine 6(2): e1000002. doi:10.1371/journal.pmed.1000002

Sassetti CM, Boyd DH, and Rubin EJ. 2003. Genes required for mycobacterial growth defined by high density mutagenesis. Molecular Microbiology 48:77-84

Siddiqi N, Das R, Pathak N, Banerjee S, Ahmed N, Katoch VM, and Hasnain SE. 2004. Mycobacterium tuberculosis isolate with a distinct genomic identity overexpresses a tap-like efflux pump. Infection 32:109-111. 10.1007/s15010-004-3097-x

Singh A, Jain S, Gupta S, Das T, and Tyagi AK. 2003. mymA operon of Mycobacterium tuberculosis: its regulation and importance in the cell envelope. FEMS Microbiology Letters 227:53-63.

Sirakova TD, Dubey VS, Kim HJ, Cynamon MH, and Kolattukudy PE. 2003. The largest open reading frame (pks12) in the Mycobacterium tuberculosis genome is involved in pathogenesis and dimycocerosyl phthiocerol synthesis. Infection and Immunity 71:3794-3801.

Sreevatsan S, Pan X, Stockbauer KE, Connell ND, Kreiswirth BN, Whittam TS, and Musser JM. 1997. Restricted structural gene polymorphism in the Mycobacterium tuberculosis complex indicates evolutionarily recent global dissemination. Proceedings of the National Academy of Sciences of the United States of America 94:9869-9874.

Srivastava S, Ayyagari A, Dhole TN, Nyati KK, and Dwivedi SK. 2009. emb nucleotide polymorphisms and the role of embB306 mutations in Mycobacterium tuberculosis 
656

657

658

659

660

661

662

663

664

665

666

667

668

669

670

671

672

673

674

675

676

677

678

679

680

681

682

683

684

685

686

687

688

689

690

691

692

693

694

695

696

697

698

699

resistance to ethambutol. International Journal of Medical Microbiology : IJMM 299:269-280. 10.1016/j.ijmm.2008.07.001

Taniguchi H, Aramaki H, Nikaido Y, Mizuguchi Y, Nakamura M, Koga T, and Yoshida S. 1996. Rifampicin resistance and mutation of the rpoB gene in Mycobacterium tuberculosis. FEMS Microbiology Letters 144:103-108.

Telenti A, Philipp WJ, Sreevatsan S, Bernasconi C, Stockbauer KE, Wieles B, Musser JM, and Jacobs WR, Jr. 1997. The emb operon, a gene cluster of Mycobacterium tuberculosis involved in resistance to ethambutol. Nature Medicine 3:567-570.

Thierry D, Cave MD, Eisenach KD, Crawford JT, Bates JH, Gicquel B, and Guesdon JL. 1990. IS6110, an IS-like element of Mycobacterium tuberculosis complex. Nucleic acids research 18:188.

Tho DQ, Torok ME, Yen NT, Bang ND, Lan NT, Kiet VS, van Vinh Chau N, Dung NH, Day J, Farrar J, Wolbers M, and Caws M. 2012. Influence of antituberculosis drug resistance and Mycobacterium tuberculosis lineage on outcome in HIV-associated tuberculous meningitis. Antimicrobial Agents and Chemotherapy 56:3074-3079. 10.1128/AAC.00319-12

Thwaites G, Caws M, Chau TT, D'Sa A, Lan NT, Huyen MN, Gagneux S, Anh PT, Tho DQ, Torok E, Nhu NT, Duyen NT, Duy PM, Richenberg J, Simmons C, Hien TT, and Farrar J. 2008. Relationship between Mycobacterium tuberculosis genotype and the clinical phenotype of pulmonary and meningeal tuberculosis. Journal of Clinical Microbiology 46:1363-1368. 10.1128/JCM.02180-07

Thwaites GE , van Toorn R and Schoeman J. 2013. Tuberculous meningitis: more questions, still too few answers. Lancet Neurol 12:999-1010

Tsenova L, Ellison E, Harbacheuski R, Moreira AL, Kurepina N, Reed MB, Mathema B, Barry CE, 3rd, and Kaplan G. 2005. Virulence of selected Mycobacterium tuberculosis clinical isolates in the rabbit model of meningitis is dependent on phenolic glycolipid produced by the bacilli. The Journal of Infectious Diseases 192:98-106. $10.1086 / 430614$

Tsolaki AG, Hirsh AE, DeRiemer K, Enciso JA, Wong MZ, Hannan M, Goguet de la Salmoniere YO, Aman K, Kato-Maeda M, and Small PM. 2004. Functional and evolutionary genomics of Mycobacterium tuberculosis: insights from genomic deletions in 100 strains. Proceedings of the National Academy of Sciences of the United States of America 101:4865-4870. 10.1073/pnas.0305634101

Van der Auwera GA, Carneiro M, Hartl C, Poplin R, del Angel G, Levy-Moonshine A, Jordan T, Shakir K, Roazen D, Thibault J, Banks E, Garimella K, Altshuler

D, Gabriel S and DePristo M. 2013. From FastQ Data to High-Confidence Variant Calls: The Genome Analysis Toolkit Best Practices Pipeline. Current

Protocols in Bioinformatics 43:11.10.1-11.10.33

van Embden JD, Cave MD, Crawford JT, Dale JW, Eisenach KD, Gicquel B, Hermans P, Martin C, McAdam R, Shinnick TM, and Small PM. 1993. Strain identification of Mycobacterium tuberculosis by DNA fingerprinting: recommendations for a standardized methodology. Journal of Clinical Microbiology 31:406-409. 
700

701

702

703

704

705

706

707

708

709

710

711

712

713

714

715

716

717
Velmurugan K, Chen B, Miller JL, Azogue S, Gurses S, Hsu T, Glickman M, Jacobs WR, Jr., Porcelli SA, and Briken V. 2007. Mycobacterium tuberculosis nuoG is a virulence gene that inhibits apoptosis of infected host cells. PLoS Pathogens 3:e110. 10.1371/journal.ppat.0030110

Wang XD, Gu J, Wang T, Bi LJ, Zhang ZP, Cui ZQ, Wei HP, Deng JY, and Zhang XE. 2011. Comparative analysis of mycobacterial NADH pyrophosphatase isoforms reveals a novel mechanism for isoniazid and ethionamide inactivation. Molecular Microbiology 82:1375-1391. 10.1111/j.1365-2958.2011.07892.x

Zheng H, Lu L, Wang B, Pu S, Zhang X, Zhu G, Shi W, Zhang L, Wang H, Wang S, Zhao G, and Zhang Y. 2008. Genetic basis of virulence attenuation revealed by comparative genomic analysis of Mycobacterium tuberculosis strain H37Ra versus H37Rv. PloS One 3:e2375. 10.1371/journal.pone.0002375

Zumla A, George A, Sharma V, Herbert RH, Baroness Masham of I, Oxley A, and Oliver M. 2015. The WHO 2014 global tuberculosis report--further to go. The Lancet Global Health 3:e10-12. 10.1016/S2214-109X(14)70361-4 
1

Distribution of single nucleotide polymorphisms in isolates CSF3053, 46-5069 and 4313838.

Venn diagram showing the distribution of the single nucleotide polymorphisms (SNPs) observed in isolates CSF-3053 (blue), 46-5069(red) and 43-13838(yellow). CSF3053, 46-5069 and 43-13838 have 10, 7 and 49 unique SNPs respectively. 43-13838 and CSF3053 have 23 SNPs in common, CSF3053 and 46-5069 have 99 SNPs in common, while 43-13838 and 465069 have 14 SNPs in common. 2,202 SNPs are common to all isolates.

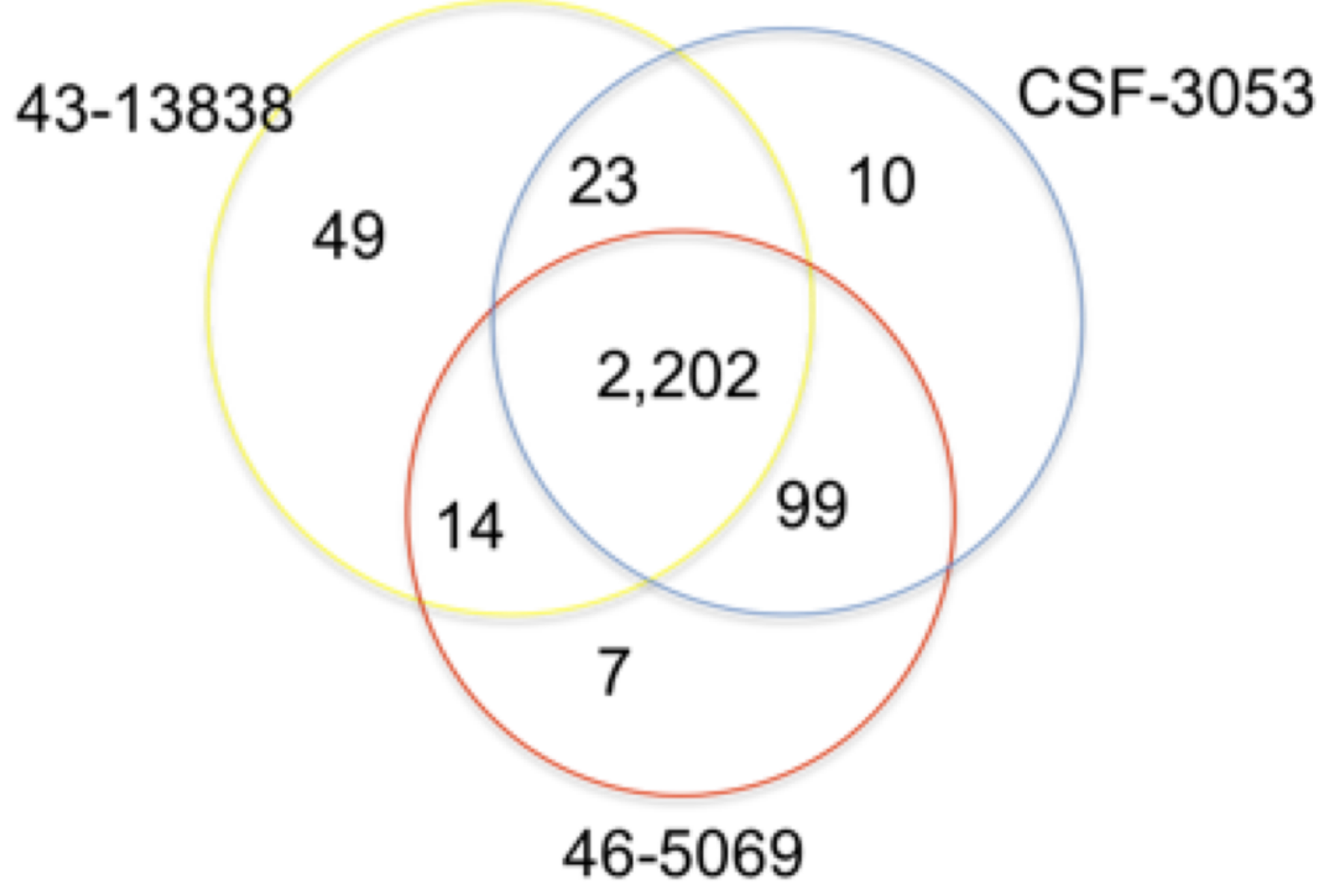




\section{Table 1 (on next page)}

Statistics of whole genome sequencing, genome assembly and annotation. 
1 Tables and captions

\section{Table 1: Statistics of whole genome sequencing, genome assembly and annotation}

3

4

5

\begin{tabular}{|c|c|c|c|c|c|c|c|c|c|c|}
\hline $\begin{array}{l}\text { Isolate } \\
7 \\
8 \\
9 \\
10\end{array}$ & Total reads & $\begin{array}{l}\% \text { of reads } \\
\text { mapped to } \\
\text { Reference }\end{array}$ & $\begin{array}{l}\% \text { of } \\
\text { Referenc } \\
\text { e covered }\end{array}$ & $\begin{array}{l}\text { Number of } \\
\text { contigs }\end{array}$ & N50 & $\begin{array}{l}\text { Fold coverage } \\
\text { of positions in } \\
\text { the genome }\end{array}$ & $\begin{array}{l}\mathrm{GC} \\
\text { content } \\
(\%)\end{array}$ & $\begin{array}{l}\text { Number } \\
\text { of } \\
\text { predicted } \\
\text { Genes }\end{array}$ & $\begin{array}{l}\text { No. of } \\
\text { predicted } \\
\text { RNA genes }\end{array}$ & $\begin{array}{l}\text { No. of } \\
\text { predicted } \\
\text { pseudo genes }\end{array}$ \\
\hline 19SF-3053 & $50,004,564$ & 99.96 & 99.78 & 159 & 69,028 & 1329.0 & 65.5 & 4153 & 48 & 62 \\
\hline $128-5069$ & $44,478,206$ & 98.67 & 99.82 & 173 & 63,852 & 920 & 65.5 & 4159 & 48 & 63 \\
\hline $\begin{array}{l}13 \\
43-13838 \\
14\end{array}$ & $40,767,970$ & 98.69 & 99.80 & 177 & 63,019 & 920 & 65.5 & 4150 & 48 & 67 \\
\hline
\end{tabular}

15 statistics of the whole genome sequence data, mapping of reads, assembly of draft genome and annotation for isolates CSF-3053, 46-5069 and 43-

16 13838. Length of reference genome (M. tuberculosis H37Rv, NC_000962.3) is 4,411,532 base pairs, GC: guanine/ cytocine. 


\section{Table 2 (on next page)}

Regions of deletion common to isolates CSF-3053, 46-5069 and 43-13838.

Regions of deletion and affected open reading frames found in isolates CSF-3053, 46-5069 and 43-13838. All regions were confirmed by PCR reaction as described in methods. 
2 Table 2: Regions of deletion common to isolates CSF-3053, 46-5069 and 43-13838

3

4

\begin{tabular}{|c|c|c|c|}
\hline $\begin{array}{l}\text { Region in reference } \\
\text { genome (H37Rv, } \\
\text { NC_000962.3) }\end{array}$ & Length & $\begin{array}{l}\text { Region of } \\
\text { difference }\end{array}$ & $\begin{array}{l}\text { Open reading frame } \\
(\mathrm{ORF}) \text { affected }\end{array}$ \\
\hline $1718912-1721213$ & 2302 & RD147c [57] & $\begin{array}{l}R v 1526 c \\
R v 1525(w b b L 2) \\
R v 1526 c\end{array}$ \\
\hline $3501225-3501723$ & 499 & This study & $R v 3135$ \\
\hline $4092082-4092921$ & 840 & RD239[57] & $R v 3651$ \\
\hline
\end{tabular}

5

6 Regions of deletion and affected open reading frames found in isolates CSF-3053, 46-5069 and 43-13838. All regions were confirmed

7 by PCR reaction as described in methods. 


\section{Table 3 (on next page)}

Common SNPs found in drug resistance related genes in isolates CSF-3053, 46-5069 and 43-13838.

The reference genome positions, nucleotide change, amino acid change and effect of single nucleotide polymorphisms in drug resistance related genes that are common to isolates CSF3053, 46-5069 and 43-13838. The protein variation was determined by Protein Variation Effect Analyzer (PROVEAN), a web based protein variation analysis tool (Choi et al. 2012) 
1 Table 3: Common SNPs found in drug resistance related genes in isolates CSF-3053, 46-5069 and 43-13838

\begin{tabular}{|c|c|c|c|c|c|c|}
\hline $\begin{array}{l}\text { Position in } \\
\text { reference genome } \\
\text { (H37Rv, } \\
\text { NC_000962.3) }\end{array}$ & $\begin{array}{l}\text { Nucleotide } \\
\text { change }\end{array}$ & $\begin{array}{l}\text { Amino acid } \\
\text { change }\end{array}$ & $\begin{array}{l}\text { Protein } \\
\text { variation effect }\end{array}$ & Gene & Associated drug & References \\
\hline 6112 & $\mathrm{G}>\mathrm{C}$ & Met291Ile & Deleterious & gyrB & Quinolones & $\begin{array}{l}\text { (Guillemin et } \\
\text { al. 1998) }\end{array}$ \\
\hline 7362 & $\mathrm{G}>\mathrm{C}$ & Glu21Gln & Neutral & gyrA & Quinolones & $\begin{array}{l}\text { (Guillemin et } \\
\text { al. 1998) }\end{array}$ \\
\hline 7585 & $\mathrm{G}>\mathrm{C}$ & Ser95Thr & Neutral & gyrA & Quinolones & $\begin{array}{l}\text { (Guillemin et } \\
\text { al. 1998; } \\
\text { Kapur et al. } \\
\text { 1995) }\end{array}$ \\
\hline 8452 & $\mathrm{C}>\mathrm{T}$ & Ala384Val & Deleterious & gyrA & Quinolones & $\begin{array}{l}\text { (Guillemin et } \\
\text { al. 1998) }\end{array}$ \\
\hline 9143 & $\mathrm{~T}>\mathrm{C}$ & Ile614Ile & & gyrA & Quinolones & $\begin{array}{l}\text { (Guillemin et } \\
\text { al. 1998) }\end{array}$ \\
\hline 9260 & $\mathrm{G}>\mathrm{C}$ & Leu653Leu & & gyrA & Quinolones & (Guillemin et \\
\hline
\end{tabular}




\begin{tabular}{|c|c|c|c|c|c|c|}
\hline & & & & & & al. 1998) \\
\hline 9304 & $\mathrm{G}>\mathrm{A}$ & $\begin{array}{l}\text { Gly668Asp } \\
\text { (N) }\end{array}$ & Neutral & gyrA & Quinolones & $\begin{array}{l}\text { (Guillemin et } \\
\text { al. 1998) }\end{array}$ \\
\hline 412280 & $\mathrm{~T}>\mathrm{G}$ & His481Gln & Neutral & iniA & Ethambutol & $\begin{array}{l}\text { (Ramaswam } \\
\text { y et al. 2003) }\end{array}$ \\
\hline 575368 & $\mathrm{~T}>\mathrm{C}$ & Asp7Asp & & $R v 0486$ & Isoniazid/Ethionamide & $\begin{array}{l}\text { (Projahn et } \\
\text { al. 2011) }\end{array}$ \\
\hline 763031 & $\mathrm{~T}>\mathrm{C}$ & Ala1081Ala & & rpoB & Rifampicin & $\begin{array}{l}\text { (Taniguchi et } \\
\text { al. 1996) }\end{array}$ \\
\hline 763531 & $\mathrm{G}>\mathrm{C}$ & Pro54Pro & & rpoC & Rifampicin & $\begin{array}{l}\text { (Comas et al. } \\
\text { 2012) }\end{array}$ \\
\hline 763884 & $\mathrm{C}>\mathrm{T}$ & Ala172Val & Neutral & rpoC & Rifampicin & $\begin{array}{l}\text { (Comas et al. } \\
\text { 2012) }\end{array}$ \\
\hline 763886 & $\mathrm{C}>\mathrm{A}$ & Arg173Arg & & rpoC & Rifampicin & $\begin{array}{l}\text { (Comas et al. } \\
\text { 2012) }\end{array}$ \\
\hline 1406312 & $A>G$ & His343His & & $R v 1258 c$ & Streptomycin & $\begin{array}{l}\text { (Siddiqi et al. } \\
\text { 2004) }\end{array}$ \\
\hline 1417019 & $\mathrm{C}>\mathrm{T}$ & Cys110Tyr & Deleterious & $e m b R$ & Ethambutol & (Ramaswam \\
\hline
\end{tabular}




\begin{tabular}{|c|c|c|c|c|c|c|}
\hline & & & & & & y et al. 2000) \\
\hline 1674162 & $\mathrm{C}>\mathrm{T}$ & Gly241Gly & & fabG1 & Isoniazid & $\begin{array}{l}\text { (Lavender et } \\
\text { al. 2005) }\end{array}$ \\
\hline 1792777 & $\mathrm{~T}>\mathrm{C}$ & Ile322Val & Neutral & $R v 1592 c$ & Isoniazid & $\begin{array}{l}\text { (Ramaswam } \\
\text { y et al. 2003) }\end{array}$ \\
\hline 1792778 & $\mathrm{~T}>\mathrm{C}$ & Glu321Glu & & $R v 1592 c$ & Isoniazid & $\begin{array}{l}\text { (Ramaswam } \\
\text { y et al. 2003) }\end{array}$ \\
\hline 2154724 & $\mathrm{C}>\mathrm{A}$ & Arg463Leu & Neutral & katG & Isoniazid & $\begin{array}{l}\text { (Heym et al. } \\
1995)\end{array}$ \\
\hline 2518132 & $\mathrm{C}>\mathrm{T}$ & Thr6Thr & & kas $A$ & Isoniazid & $\begin{array}{l}\text { (Lee et al. } \\
1999)\end{array}$ \\
\hline 2519048 & $\mathrm{G}>\mathrm{A}$ & Gly312Ser & Neutral & kas $A$ & Isoniazid & $\begin{array}{l}\text { (Lee et al. } \\
1999)\end{array}$ \\
\hline 2521342 & $\mathrm{~T}>\mathrm{C}$ & Asp200Asp & & accD6 & Isoniazid & $\begin{array}{l}\text { (Ramaswam } \\
\text { y et al. 2003) }\end{array}$ \\
\hline 3154414 & $\mathrm{~A}>\mathrm{G}$ & Ile73Thr & Neutral & efpA & Isoniazid & $\begin{array}{l}\text { (Ramaswam } \\
\text { y et al. 2003) }\end{array}$ \\
\hline 3571834 & $\mathrm{~T}>\mathrm{G}$ & Gln237Pro & Neutral & nudC & Isoniazid/Ethionamide & (Wang et al. \\
\hline
\end{tabular}




\begin{tabular}{|c|c|c|c|c|c|c|}
\hline & & & & & & 2011) \\
\hline 3647041 & $\mathrm{~A}>\mathrm{G}$ & Ser257Pro & Neutral & $r m l D$ & Ethambutol & $\begin{array}{l}\text { (Ramaswam } \\
\text { y et al. 2000) }\end{array}$ \\
\hline 3647591 & $\mathrm{~A}>\mathrm{G}$ & Asn73Asn & & $r m l D$ & Ethambutol & $\begin{array}{l}\text { (Ramaswam } \\
\text { y et al. 2000) }\end{array}$ \\
\hline 4049254 & $\mathrm{G}>\mathrm{A}$ & Leu243Leu & & folP1 & Para-aminosalicylic acid & $\begin{array}{l}\text { (Mathys et } \\
\text { al. 2009) }\end{array}$ \\
\hline 4240671 & $\mathrm{C}>\mathrm{T}$ & Thr270Ile & Neutral & $e m b C$ & Ethambutol & $\begin{array}{l}\text { (Ramaswam } \\
\text { y et al. 2000) }\end{array}$ \\
\hline 4241042 & $A>G$ & Asn394Asp & Deleterious & $e m b C$ & Ethambutol & $\begin{array}{l}\text { (Ramaswam } \\
\text { y et al. 2000) }\end{array}$ \\
\hline 4242643 & $\mathrm{C}>\mathrm{T}$ & Arg927Arg & & $e m b C$ & Ethambutol & $\begin{array}{l}\text { (Ramaswam } \\
\text { y et al. 2000) }\end{array}$ \\
\hline 4243580 & $\mathrm{G}>\mathrm{A}$ & Val116Val & & $e m b A$ & Ethambutol & $\begin{array}{l}\text { (Telenti et al. } \\
\text { 1997) }\end{array}$ \\
\hline 4244420 & $\mathrm{G}>\mathrm{C}$ & Val396Val & & $e m b A$ & Ethambutol & $\begin{array}{l}\text { (Telenti et al. } \\
\text { 1997) }\end{array}$ \\
\hline 4245969 & $\mathrm{C}>\mathrm{T}$ & Pro913Ser & Deleterious & $e m b A$ & Ethambutol & (Ramaswam \\
\hline
\end{tabular}




\begin{tabular}{|c|c|c|c|c|c|c|}
\hline & & & & & & $\begin{array}{l}\text { y et al. 2000; } \\
\text { Telenti et al. } \\
1997 \text { ) }\end{array}$ \\
\hline 4247578 & $\mathrm{G}>\mathrm{A}$ & Leu355Leu & & $e m b B$ & Ethambutol & $\begin{array}{l}\text { (Telenti et al. } \\
\text { 1997) }\end{array}$ \\
\hline 4247646 & $\mathrm{~A}>\mathrm{C}$ & Glu378Ala & Neutral & $e m b B$ & Ethambutol & $\begin{array}{l}\text { (Telenti et al. } \\
\text { 1997) }\end{array}$ \\
\hline 4407588 & $\mathrm{~T}>\mathrm{C}$ & Ala205Ala & & $r s m G$ & Streptomycin & $\begin{array}{l}\text { (Okamoto et } \\
\text { al. 2007) }\end{array}$ \\
\hline 4407873 & $\mathrm{C}>\mathrm{A}$ & Val110Val & & $r s m G$ & Streptomycin & $\begin{array}{l}\text { (Okamoto et } \\
\text { al. 2007) }\end{array}$ \\
\hline
\end{tabular}

2 The reference genome positions, nucleotide change, amino acid change and effect of single nucleotide polymorphisms in drug

3 resistance related genes that are common to isolates CSF3053, 46-5069 and 43-13838. The protein variation was determined by

4 Protein Variation Effect Analyzer (PROVEAN), a web based protein variation analysis tool (Choi et al. 2012) 